\title{
INVESTIGATION OF FORECASTED RISK INTERRELATIONSHIP: BASE ON GARCH MODEL, CAUSALITY IN CHINA MARKETS
}

\author{
Shu-Shian LIN \\ Department of International Business Administration, Chinese Culture University, \\ 55 Hwa-Kang Road, Yang-Ming-Shan, Taipei, Taiwan, Republic of China \\ E-mail:sslin@cycu.org.tw
}

Received 06 April 2013; accepted 27 August 2013

\begin{abstract}
This paper used data from the Shenzhen and Shanghai stock markets to simulate the adjusted volatility, and applied time series methods to realize the relationships of the volatilities between the two markets. The unit root test, and co-integration analysis to show whether it exists equilibrium relationship. The result showed that it presented the co-integrated vectors between the volatilities of Shanghai and Shenzhen Stock Exchanges during the research period, and it made the regression more meaningful. Finally, it also showed that the volatility exerted one way influence between these two markets. It significantly rejected for a null hypothesis of Shanghai stock market does not granger caused Shenzhen stock market, and the results of simulated volatilities were consistent with the results in reality.
\end{abstract}

Keywords: forecast, GARCH, risk, interrelationship, volatility, causality.

JEL Classification: G15, G17.

\section{Introduction}

Since 1978, industrial reforms have caused a rapid structural change in China. The rapid emergence of such reforms has stimulated demand for financial services. The Shenzhen and Shanghai stock markets are the two major exchanges in China. At the end of 2000, both domestic and foreign shares were listed on the Shanghai and Shenzhen Stock Exchanges, and the "open door" policy increased the need for international financial services, including trade finance and foreign currency borrowing.

China's domestic shares, sometimes called A shares, can only be transacted by residents of China, and are traded in Chinese Yuan, RMB (Ren Min Bi). The foreign shares, sometimes called B shares, can only be transacted by foreign investors, and are traded in US Dollars on the Shanghai Stock Exchange and H.K. (Hong Kong), in US Dollars on the Shenzhen Stock Exchange. Some Chinese listed firms issue only A shares, some only B shares, and some issue both A and B shares. Since February 2001, B share ownership has been extended to domestic investors with legal foreign currency $(\mathrm{He}, \mathrm{Wu}$ 2006; Brown, Mitchell 2008). 
Because the Shenzhen and Shanghai stock markets are the two major main stock markets in China. It is important to consider their exposure to broader market risk. Sheu and Chen (2012) empirically explore the impact from idiosyncratic risk on the systemic risk of the system and attempt to investigate the links between other stock markets due to financial crises, systemic risk, etc. This study thus focuses on a common index of risk, namely volatility, to examine how volatility is transferred. The first step is to calculate the variance of returns for each stock market, then to define the variance of returns as the total risk, and finally to apply the GARCH model as the adjusted volatility.

Therefore, according to different studies, it remains an issue worth to discuss the volatility causality of the emerging Chinese stock markets in Shanghai and Shenzhen. This study differs from previous studies in that it applies real market data to adjust the predicted volatility obtained using the GARCH model. The remainder of this study is organized as follows: Section 1 considers the literature review; Section 2 then describes the collected data and simulation design; finally, the last Section describes the results and gives conclusions.

\section{Literature review}

The GARCH model was introduced and developed to resolve problems of clustering in financial data. This model depends on heteroskedasticity to track and manage changing volatility, and this method of forecasting volatility recently was commonly used. The idea that the volatility of asset returns was time varying and displayed clustering was originally from Bollerslev (1986). Boudoukh et al. (1998) assumed that returns represented that current risk from the recent past was better than returns from the distant past. Finally, GARCH models have proven themselves the best methods to represent for the standard deviation (Nwogugu 2006).

Eberlein et al. (2003) showed that volatility was stochastic. To solve the problems associated with the assumption of constant volatility, Barone-Adesi et al. (1999, 2002) allowed the volatilities of historical returns to change, because this involved the calibration of the appropriate GARCH model. Liu and Hung (2010) investigated daily volatility forecasting for the Standard \& Poor's 100 stock index series to identify the essential source of performance improvements by distributional assumption and used GARCH to examine volatility specifications. Tseng et al. (2009) apply hybrid methodology to predict stock volatility. Akgiray (1989) utilized data obtained from the Center for Research in Security Prices (CRSP) to examine whether the GARCH model outperformed than other models in forecasting. The comparison results showed that forecasts of return variances of stock indices based on the GARCH model are superior predictors to others which made using other models in out-of-samples.

Another improvement was achieved by Giot and Laurent (2004) using daily realized volatility at the cost of obtaining intraday data. Chu and Freund (1996) selected the raw data to calculate daily returns for the S\&P 500 and the S\&P 100 indices. The result showed that the use of GARCH models significantly reduces model mispricing when forecasting option values using only data on historical returns. Otherwise, Hull and 
White (1998) proposed a procedure for using a GARCH model together with historical simulation when calculating value at risk. They obtained mixed results for stock index investments. Wang (2009) apply GARCH model to forecast stock index. Hung et al. (2013) improve GARCH-based volatility forecasts with Range-based estimators. Tompkins and D'Ecclesia (2006) observed that the simulated options payoff values utilizing the GARCH $(1,1)$ model did not differ significantly from the actual payoff values.

Swanson (1987) examined the relationship between Eurodollar deposit rates and yields on negotiable US certificates of deposit during 1979-1983, allowing for two-way feedback effects by employing the Granger (1969) causality test (Kaen, Hachey 1983). Eun and Shim (1989) verified that the stock markets of various countries can nearly complete information transmission within one or two days. Additionally, Arshanapalli et al. (1995) examine the stock market linkages between the United State and major markets in Asia to clarify developments and changes in information transmission in international stock markets.

Some studies examined major stock markets (Chan et al. 1992), others focused on continental Europe (Choudhry 1996), and others explored the Asia-Pacific (Chung, Liu 1994; Arshanapalli et al. 1995) or tested the co-integration of the United States and Asian stock markets (Ghosh et al. 1999). Additionally, Jang and Sul (2002) employed co-integration to discuss the relationships among stock markets in Thailand, Indonesia, Korea S., Japan, Hong Kong, Taiwan, and Singapore.

Interrelationships with international stock markets are analyzed using various classifications of regional economies. Some studies investigated relationships with the major global stock markets (Chan et al. 1992). Chang et al. (2000) utilized the VAR model to examine the Greater China Economic Area, including the five ethnic Chinese area financial markets of Taiwan, Hong Kong, Singapore, Shanghai, and Shenzhen.

\section{Methodology and empirical results}

The data used to test for the returns are daily stock price index data published by the Shanghai (Shanghai Composite Index series) and Shenzhen (Shenzhen Composite Index series) securities exchanges in China. The Shanghai and Shenzhen stock price index data sample period is from January 4, 2005 to December 31,2012 , for a total of 1944 daily settlement price, $\mathrm{S}_{\mathrm{tj}}$ are obtained, which is collected from the Taiwan Economic Journal (TEJ) database, and the methodology process is shown as Figure 1.

Given a historical daily price series $S_{t j}$, returns are computed using continuously compound interest rate:

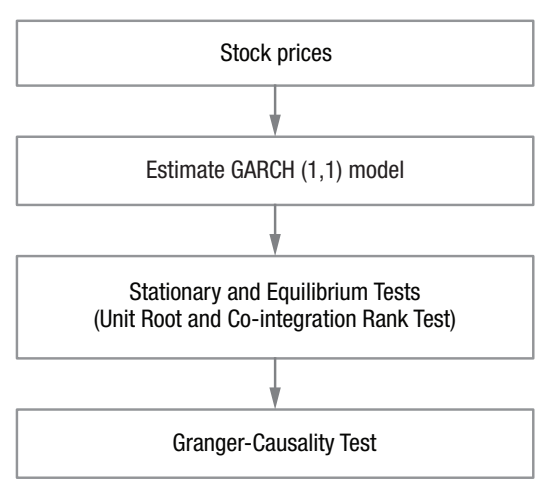

Fig. 1. The methodology process 


$$
R_{t j}=\frac{S_{t j}-S_{t j-1}}{S_{t j-1}} \text { for } j=1,2, \ldots, N .
$$

We assume the volatility term as the form of a GARCH $(1,1)$ model in this case according to the Bollerslev (1986) formulation to estimate the parameters, $\omega, \alpha$ and $\beta$, by the following expression:

$$
\sigma_{t j}=\sqrt{\sigma_{t j}^{2}}=\sqrt{\omega+\alpha v_{t j-1}^{2}+\beta \sigma_{t j-1}^{2}} .
$$

Following the effect of GARCH $(1,1)$ model, we try to find out the adjusted GARCH volatility on the day $t$ by the data in the market shown on day $t-1$ :

$$
\operatorname{adj} \tilde{\sigma}_{t j}=\sqrt{\omega^{*}+\alpha * v_{t j-1}^{* 2}+\beta^{*} \sigma_{t j-1}^{* 2}},
$$

where $\operatorname{adj} \tilde{\sigma}_{t j}$ is the estimated volatility path of GARCH $(1,1)$ model for the entire period using $\omega^{*}, \alpha^{*}, \beta^{*}$ get from equation (3), and the $v_{t j-1,}, \sigma_{t j-1}$ are data from the market. For the original path of daily returns and disturbances, the statistical properties are shown in Table 1. Figure 2 presented the price paths of the volatilities, seemingly the PRD (Pseudo Random Disturbances) approach (Lo, Lin 2010).

Table 1. The statistics of the GARCH volatility of the Shanghai and Shenzhen Composite Index returns, 2005-2012

\begin{tabular}{lcc}
\hline \multicolumn{1}{c}{ Statistics } & Shanghai Composite Index & Shenzhen Composite Index \\
\hline$\mu$ & 0.0170 & 0.0189 \\
\hline$\sigma$ & 0.0055 & 0.0052 \\
\hline Skewness & 0.8341 & 0.9271 \\
\hline Kurtosis & 2.5771 & 2.7360 \\
\hline
\end{tabular}

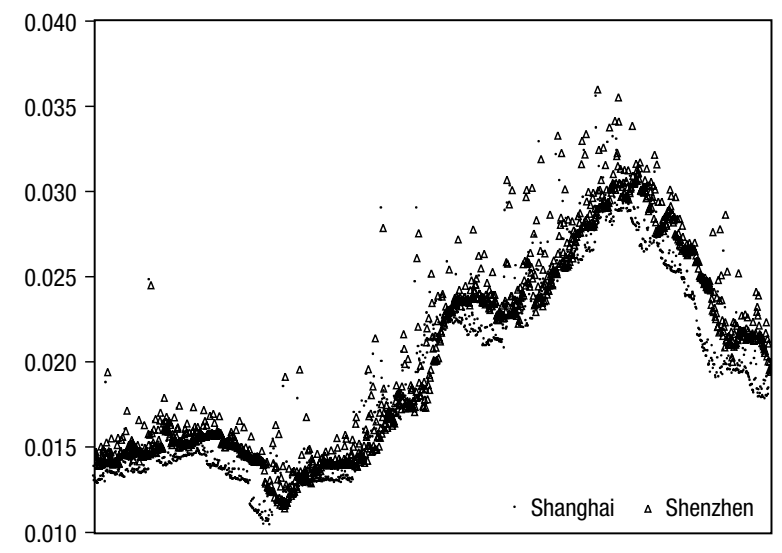

Fig. 2. The paths of the GARCH volatility of the Shanghai and Shenzhen Composite Index returns 
Table 1 showed the statistics of the GARCH volatility of the Shanghai and Shenzhen Composite Index returns. In the Shanghai and Shenzhen Composite Index returns, the basic descriptive statistics on average, deviation, skewness and kurtosis were not far away from each other. Therefore, properties of the GARCH volatility of these two stock markets were not too different to be compared with. Figure 2 presented the paths of the GARCH volatility of the Shanghai and Shenzhen Composite Index returns. The trends of these two paths were similar, and it seemed to be a linkage between the GARCH volatility of the Shanghai and Shenzhen Composite Index returns.

\subsection{Stationary and equilibrium tests}

More recent studies have largely applied the standard ADF (augmented Dickey-Fuller) test to avoid "spurious regression", and the series must be carefully examined for "stationary". Since the non-stationary regression invalidate numerous standard empirical results, econometrists developed a testing method, known as the "unit-root" test, for examining the stationary of time series. Numerous authors have noted that numerous macroeconomic and financial time series, including stock price series, contain unit roots dominated by stochastic trends. This investigation uses Akaike's information criterion (AIC) (Akaike 1973) to optimize the number of lags. The empirical results show that numerous macroeconomic and financial time series, including stock price series, contain unit roots dominated by stochastic trends. This study first utilizes the ADF test to test the stationary of each series. The Phillips-Perron test is also used to test the stationary of different considered series. The model selection procedure was that proposed by Doldado et al. (1990). This model includes a drift and a time trend, presented as the following equation, and Table 2 listed the results of the unit root test:

$$
\Delta Q_{T}=\alpha+\gamma T+\delta P_{T-1}+\sum_{i=1}^{p} \beta_{i} \delta Q_{T-i}+\varepsilon_{T} .
$$

Table 2. Unit root test

\begin{tabular}{lccc}
\hline & $\begin{array}{c}\text { ADF test statistic } \\
(\mathrm{p} \text {-value })\end{array}$ & $\begin{array}{c}1^{\text {st }} \text { difference test statistic } \\
(\mathrm{p} \text {-value })\end{array}$ & Critical value (1\%) \\
\hline Shanghai & $-1.368(0.1713)$ & $-32.912(0.0000)$ & -3.437 \\
\hline Shenzhen & $-1.748(0.0806)$ & $-31.771(0.0000)$ & -3.437 \\
\hline
\end{tabular}

Notes: 1 st difference are the symbols for the ADF 1st difference test statistic.

The results suggested strong evidences that both markets are stationary at first difference. Then, the co-integration is employed to identify the equilibrium relationship between these two markets. Several methods of estimating co-integration have been applied to capture the long-term equilibrium relationship among the variables. Regarding the long-term relationship between variables, the rank of matrix $\Pi$ represents the number of linearly independent and stationary linear combinations of the variables. We construct a p-dimensional vector autoregressive model with Gaussian errors expressed by its first-difference error-correction form (Johansen 1988; Johansen, Juselius 1990). 
Johansen (1988) and Johansen and Juselius (1990) suggested two test statistics for identifying the number of co-integrating vectors (or the rank of $\Pi$ ), namely the Trace ( Tr) and maximum eigenvalue $(\mathrm{L}-\max )$ statistics. Therefore, testing for co-integration involves testing for the rank of the $\Pi$ matrix $r$ by examining whether the eigenvalues of $\Pi$ differ significantly from zero. The literature terms this long-term equilibrium relationship co-integration. Johansen's co-integration test is well known to be highly sensitive to lag length selection. Table 3 lists the results of the co-integration rank test.

Table 3. Co-integration rank test

\begin{tabular}{cccc}
\hline & Eigenvalue & Trace statistic & Critical value (1\%) \\
\hline Rank $=0^{* *}$ & 0.0107 & 22.9051 & 20.04 \\
\hline Rank $\leq 1$ & 0.0010 & 1.9981 & 6.65 \\
\hline
\end{tabular}

Note: $*(* *)$ denotes rejection of the hypothesis at $5 \%(1 \%)$ significance level.

In Table 3, it showed that Trace ( $\mathrm{Tr}$ ) statistics propose that co-integration vector exists between the two markets. The result shows that it is able to refuse the $r=0$ hypothesis under $1 \%$ significance, showing co-integrated vectors between the volatility of Shanghai and Shenzhen Stock Exchanges during this period.

\subsection{The Granger causality test}

The Granger causality test the feedback (bi-directional), one-way causality of the variables, or finally whether it would not influence each other. The series $Y_{t}$ fails to Granger cause $W_{t}$ if $\beta_{1}(i)=0(i=1,2,3, n)$; and the series $W_{t}$ fails to cause $Y_{t}$ if $\beta_{0}(j)=0(j=$ $1,2,3, m)$. Considering two series, $Y_{t}$ and $W_{t}$, the Granger causality test is in the form as follows (Huang, Lin 2008):

$$
\begin{gathered}
Y_{t}=\alpha_{1}+\sum_{i=1}^{n_{1}} \alpha_{11}(i) \Delta Y_{t-i}+\sum_{j=1}^{m_{1}} \beta_{0}(j) \Delta W_{t-1}+\varepsilon_{Y t}, \\
W_{t}=\alpha_{2}+\sum_{i=1}^{n_{1}} \beta_{1}(i) \Delta Y_{t-i}+\sum_{j=1}^{m_{2}} \alpha_{22}(j) \Delta W_{t-1}+\varepsilon_{Z t},
\end{gathered}
$$

where, $\in Y_{t}$ and $\in W_{t}$ are stationary random processes intended to capture other relevant information not contained in lagged values of $Y_{t}$ and $W_{t}$. The lag lengths, $n$ and $m$, are chosen by AIC in our study. Table 4 shows the results of Granger causality test.

In Table 4, it clearly showed that the volatility of Shanghai and Shenzhen stock market has a one-way influence between the two markets, and it significantly rejected for a null hypothesis of Shanghai stock market does not granger cause Shenzhen stock market. The results were consistent with the results in reality. 
Table 4. Granger causality test

\begin{tabular}{lcc}
\hline \multicolumn{1}{c}{ Null hypothesis } & F-Statistics & P-Value \\
\hline & $2005 \sim 2012$ (raw data) & \\
\hline Shenzhen does not GC Shanghai & 1.5063 & 0.2220 \\
\hline Shanghai does not GC Shenzhen & 2.8314 & $0.0592 *$ \\
\hline & $2005 \sim 2012$ (forecasted data) & 0.2975 \\
\hline Shenzhen does not GC Shanghai & 1.2132 & $0.0020 * * *$
\end{tabular}

Notes: $(1) * * *, * *$ and $*$ denote significance at the $1 \%, 5 \%$ and $10 \%$ levels, respectively. (2) The null hypothesis, $\mathrm{H}_{0}$, is for "no causal relation". (3) GC means Granger cause.

\section{Conclusions}

In this paper, its main objective is to investigate the forecasted risk interrelationship by utilizing the GARCH model. In the Shanghai and Shenzhen Composite Index returns, the basic descriptive statistics were not far away from each other, and its properties of the GARCH volatility were not too different to compare with. To accomplish this goal of avoiding the "spurious regression", the series has to be carefully examined for "stationary". Results presents that the adjusted volatility series of the two markets cannot reject the unit root test to be non-stationary, and it reject the non-stationary unit root test at the first difference and appear stable. The Akaike's information criterion (AIC) is used to determine optimal lag number. This long-run equilibrium relationship is referred to in the literature as co-integration. The result shows that it is able to refuse no long-term equilibrium hypothesis, and presents co-integrated vectors between the volatility of Shanghai and Shenzhen Stock Exchanges during this period. Furthermore, Granger causality is applied to examine whether one-way causality, or feedback (bi-directional) exists between variables. Finally it shows that the volatility exerted one way influence between the two markets.

With the global economy being depressed, the interrelationship of risk in many countries increases progressively. For the case of economic globalization, a lot of newly countries were facing the predicaments of economy growth and development, especially for China, which opened its markets and investment in the past years. Base on the international stock markets interrelationship studies, which were classified in various regional economies, this study further investigated how the risk effects from one market to another market to make the investors detect how the market will change because of the change of another market, and it was possibly due to the stock market price. While the price changes, the risk changes, on the other hand, while the risk changes, the price changes. Therefore, the investors can apply the conclusion to make a more profitable investment decision.

For the contribution of this study, in the future lines of the similar researches could apply some simulations methods to establish the volatility relationship model among different stock markets, and these approaches might also be applied to realize how to construct the relationship model of the implied volatility. But it still exists several limitations, such as the exact raw data, model choosing, timing ability and so on, to be an empirical study for the investors. 


\section{References}

Akgiray, V. 1989. Conditional heteroscedasticity in time series of stock returns: evidence and forecasts, The Journal of Business 62(1): 55-80. http://dx.doi.org/10.1086/296451

Akaike, H. 1973. A new look at the statistical model identification, IEEE Transaction on Automatic Control 19(6): 716-723. http://dx.doi.org/10.1109/TAC.1974.1100705

Arshanapalli, B.; Doukas, J.; Lang, L. H. P. 1995. Pre and post-October 1987 stock market linkages between U.S. and Asian markets, Pacific-Basin Finance Journal 3(1): 57-73.

http://dx.doi.org/10.1016/0927-538X(94)00025-3

Barone-Adesi, G.; Giannopoulos, K.; Vosper, L. 1999. VaR without correlations for portfolios of derivative securities, Journal of Futures Markets 19(5): 583-602.

http://dx.doi.org/10.1002/(SICI)1096-9934(199908)19:5<583::AID-FUT5>3.0.CO;2-S

Barone-Adesi, G.; Giannopoulos, K.; Vosper, L. 2002. Back-testing derivative portfolios with FHS, European Financial Management 8(1): 31-58. http://dx.doi.org/10.1111/1468-036X.00175

Brown, P.; Mitchell, J. 2008. Culture and stock price clustering: evidence from the Peoples' Republic of China, Pacific-Basin Finance Journal 16(1-2): 95-120.

http://dx.doi.org/10.1016/j.pacfin.2007.04.005

Bollerslev, T. 1986. Generalized autoregressive conditional heteroskedasticity, Journal of Econometrics 31(3): 307-327. http://dx.doi.org/10.1016/0304-4076(86)90063-1

Boudoukh, J.; Richardson, M.; Whitelaw, R. 1998. The best of both words, Risk 11: 64-67.

Choudhry, T. 1996. Interdependence of stock markets: evidence from Europe during the 1920s and 1930s, Applied Financial Economics 6(3): 243-249. http://dx.doi.org/10.1080/096031096334268

Chan, K. C.; Gup, B. E.; Pan, M. S. 1992. An empirical analysis of stock prices in major Asian market and the United States, Financial Review 27(2): 289-307.

http://dx.doi.org/10.1111/j.1540-6288.1992.tb01319.x

Chung, P.; Liu, D. 1994. Common stochastic trends in Pacific Rim stock markets, Quarterly Review of Economics and Finance 34(3): 241-259. http://dx.doi.org/10.1016/1062-9769(94)90026-4

Chang, K. H.; Chou, S. L.; Wu, C. S. 2000. International transmission of stock market movements within the great China economic area, Pan-Pacific Management Review 3(2): 283-298.

Chu, S. H.; Freund, S. 1996. Volatility estimation for stock index options: a GARCH approach, Quarterly Review of Economics and Finance 36(4): 431-450.

http://dx.doi.org/10.1016/S1062-9769(96)90044-7

Doldado, J.; Jenkinson, T.; Sosvilla-Rivero, S. 1990. Cointegration and unit roots, Journal of Economic Surveys 4(3): 249-273. http://dx.doi.org/10.1111/j.1467-6419.1990.tb00088.x

Eberlein, E.; Kallsen, J.; Kristen, J. 2003. Risk management based on stochastic volatility, Journal of Risk 5(2): 19-44.

Eun, C. S.; Shim, S. 1989. International transmission of stock market movements, The Journal of Financial and Quantitative Analysis 24(2): 241-256. http://dx.doi.org/10.2307/2330774

Granger, C. W. J. 1969. Investigating causal relations by econometric models and cross-spectral, Econometric 37(3): 424-438. http://dx.doi.org/10.2307/1912791

Giot, P.; Laurent, S. 2004. Modelling daily Value-at-Risk using realized volatility and ARCH type models, Journal of Empirical Finance 11(3): 379-398.

http://dx.doi.org/10.1016/j.jempfin.2003.04.003

Ghosh, A.; Saidi, R; Johnson, K. H. 1999. Who moves the Asia-Pacific stock markets - US or Japan? Empirical evidence based on the theory of cointegration, Financial Review 34(1): 159-169. http://dx.doi.org/10.1111/j.1540-6288.1999.tb00450.x 
Hull, J.; White, A. 1998. Incorporating volatility updating into the historical simulation method for value at risk, Journal of Risk 1(1): 5-19.

He, Y.; Wu, C. 2006. Is stock price rounded for economic reasons in the Chinese markets?, Global Finance Journal 17(1): 119-135. http://dx.doi.org/10.1111/j.1540-6288.1999.tb00450.x

Huang, C. H.; Lin, S. S. 2008. The impact of WTO on international interdependence degree among United States, Korea and China, Applied Financial Economics Letters 4(6): 451-456. http://dx.doi.org/10.1080/17446540801964355

Hung, J. C.; Lou, T. W.; Wang, Y. H.; Lee, J. D. 2013. Evaluating and improving GARCH-based volatility forecasts with range-based estimators, Applied Economics 45(28): 4041-4049. http://dx.doi.org/10.1080/00036846.2012.748179

Jang, H.; Sul, W. 2002. The Asian financial crisis and the co-movement of Asian stock markets, Journal of Asian Economics 13(1): 94-104. http://dx.doi.org/10.1016/S1049-0078(01)00115-4

Kaen, F. R.; Hachey, G. A. 1983. Eurocurrency and national money market interest rates: an empirical investigation of causality, Journal of Money 15(3): 327-338.

http://dx.doi.org/10.2307/1992483

Liu, H. C.; Hung, J. C. 2010. Forecasting S\&P-100 stock index volatility: the role of volatility asymmetry and distributional assumption in GARCH models, Expert Systems with Applications 37(7): 4928-4934. http://dx.doi.org/10.1016/j.eswa.2009.12.022

Lo, K. H; Lin, S. S. 2010. Comparisons of non-parametric disturbance simulations and Monte Carlo approach, African Journal of Business Management 5(24): 10210-10220.

Nwogugu, M. 2006. Further critique of GARCH/ARMA/VAR/EVT Stochastic-Volatility models and related approaches, Applied Mathematics and Computation 182(2): 1735-1748.

http://dx.doi.org/10.1016/j.amc.2006.01.080

Swanson, P. E. 1987. Capital market integration over the past decade: the case of the US dollar, Journal of International Money and Finance 6(2): 215-225.

http://dx.doi.org/10.1016/0261-5606(87)90035-0

Sheu, H. J.; Chen, C. L. 2012. Systemic risk in Taiwan stock market, Journal of Business Economics and Management 13(5): 895-914. http://dx.doi.org/10.3846/16111699.2011.620168

Tseng, C. H.; Cheng, S. T.; Wang, Y. H. 2009. New hybrid methodology for stock volatility prediction, Expert Systems with Applications 36(2): 1833-1839.

http://dx.doi.org/10.1016/j.eswa.2007.12.004

Tompkins, R. G.; D’Ecclesia, R. L. 2006. Unconditional return disturbances: a non-parametric simulation approach, Journal of Banking \& Finance 30(1): 287-314.

http://dx.doi.org/10.1016/j.jbankfin.2005.05.001

Wang, T. H. 2009. Using neural network to forecast stock index option price: a new hybrid GARCH approach, Quality \& Quantity 43(5): 833-843. http://dx.doi.org/10.1007/s11135-008-9176-9

Shu-Shian LIN (Dr) is an Assistant Professor of Department of International Business Administration, Chinese Culture University, and holds $\mathrm{PhD}$ in the Graduate School of National Central University. His current researches focus on international relationship of stocks, momentum investment strategy and simulation of financial derivatives. 